\title{
Survey on retinopathy of prematurity (ROP) in Italy
}

Cesarina Borroni ${ }^{1,4^{*}}$, Carla Carlevaro ${ }^{2}$, Sabrina Morzenti ${ }^{3}$, Elena De Ponti ${ }^{3}$, Valentina Bozzetti ${ }^{1}$, Vito Console ${ }^{4}$, Salvatore Capobianco ${ }^{4,5}$, Paolo E Tagliabue ${ }^{1}$, on behalf of the Italian ROP study group

\begin{abstract}
Background: This study aims to investigate the incidence and the relative risk factors of retinopathy of prematurity (ROP) and posterior-ROP (P-ROP): ROP in Zone I and posterior Zone II, as well as to analyze the occurrence of surgical treatment of ROP and to evaluate the short term outcome of the disease in Italy.

Methods: It is a prospective multicenter observational study; all infants with a birth weight (BW) $\leq 750 \mathrm{~g}$ and/or a gestational age $(G A) \leq 27$ weeks born between January $1^{\text {st }} 2008$ and December $31^{\text {st }} 2009$ in 25 III level Italian neonatal intensive care units were eligible for the study.

Results: 421 infants were examined: 265 (62.9\%) developed ROP and 102 (24.2\%) P-ROP.

Following the multivariate analysis erythropoietin-therapy $(p<0.0001)$ and intraventricular hemorrhage (IVH) $(p=0.003)$ were significantly associated with ROP while gestational age $\leq 24$ weeks $(p=0.011)$ and sepsis $(p=0.002)$ were associated with the onset of P-ROP. Eighty nine infants (34\%) required surgical treatment; following the multivariate analysis P-ROP was an independent factor associated with the need of surgical treatment $(p<0.0001)$. A favorable outcome was reported in 251 (94.7\%) newborns affected by ROP. Adverse outcome occurred in 14 patients: all of them underwent surgery and showed P-ROP.

Conclusions: P-ROP is the most aggressive type of ROP. It associates with lower GA and sepsis. Obstetricians and Neonatologists must focus on the reduction of severe preterm births and on the prevention of neonatal early and late onset sepsis in order to reduce the incidence of P-ROP.
\end{abstract}

Keywords: Retinopathy of prematurity (ROP), Posterior ROP, Plus-disease, Laserterapy, Extremely preterm infants

\section{Background}

Retinopathy of prematurity (ROP) is a vasoproliferative disorder of the retina that may result in a significant loss of vision and even blindness. In recent decades the survival rate of extremely preterm infants has improved dramatically [1]. Since extremely preterm infants are at high risk of developing ROP, the number of infants with severe ROP has risen considerably in the last few years. Currently, ROP is one of the most common causes of childhood blindness [2].

In 1951, Campbell first highlighted the involvement of supplemental oxygen in the pathogenesis of ROP; the role of oxygen was subsequently reconfirmed by other

\footnotetext{
* Correspondence: cborroni@alice.it

${ }^{1}$ Neonatology and Neonatal Intensive Care Unit Fondazione MBBM, Monza, Italy

${ }^{4}$ Executive board of the Italian "ROP Study Group", Torino, Italy

Full list of author information is available at the end of the article
}

authors $[3,4]$. During the first stage of the pathogenesis of ROP, hyperoxia suppresses the activity of the vascular endothelial growth factor (VEGF) and alters the normal vascularization of the retina due to vaso-constriction and vaso-obliteration of the existing immature vessels. In the second phase of ROP, upregulation of VEGF and other growth factors, triggered by hypoxia, induces vascular overproliferation. Thus both hypoxia and hyperoxia are involved in the pathogenesis of ROP [5].

Fifty percent of extremely preterm infants show clinical signs of ROP, although this percentage varies widely. Complete recovery rate is approximately $85 \%$ [6].

Several papers have described the risk factors for ROP and have provided recommendations for the prevention of the disease [7,8]. The American Academy of Pediatrics, the American Academy of Ophthalmology and the American Association of Pediatric Ophthalmology and Strabismus

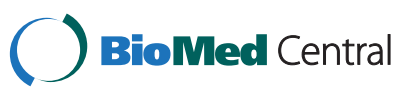


have established the screening instructions that are currently used in neonatal intensive care units (NICUs) [9-12]. According to these studies all preterm infants born at less than 30 weeks of gestation and/or with a birthweight less than $1500 \mathrm{~g}$ should undergo an indirect ophthalmoscopy of dilated eyes. The ophthalmoscopy should start from the $31^{\text {st }}$ week of postconceptional age or from the $28^{\text {th }}$ day of life. The CRYO-ROP report has defined the criteria of the "threshold ROP"; the ETROP data, published in December 2003, demonstrated a benefit of earlier treatment compared with conventional management; babies who meet ETROP criteria should be considered eligible for surgical treatment (cryo-therapy, argon or diode laser-therapy) $[12,13]$.

The aim of our prospective multicenter cohort study is to investigate the incidence and the relative risk factors of ROP and P-ROP, the incidence of surgical treatment and to evaluate the short-term outcome of the disease in Italy.

\section{Methods}

This study, promoted by the "Italian ROP study group", involved a cohort of infants born between January $1^{\text {st }}$ 2008 and December $31^{\text {st }} 2009$ with a birth weight $(\mathrm{BW}) \leq 750 \mathrm{~g}$ and/or a gestational age $(\mathrm{GA}) \leq 27$ weeks, in 25 III level Italian NICUs. Gestational age was confirmed by fetal ultrasound. In order to reduce differences in the neonatal assistance, the newborns admitted to the III level NICUs 6 hours following birth were excluded; newborns who died before discharge and newborns affected by major congenital malformations were also excluded.

The following data for each infants were recorded on a specific database: gender, race, premature rupture of membranes, chorioamnionitis, use of prenatal steroids, place of birth (inborn or outborn), fifth minute Apgar score, days of mechanical ventilation, days of parenteral nutrition, doses of erythropoietin (EPO) and blood transfusions.

The following complications of preterm birth were registered:

- intraventricular hemorrhage (IVH): any grade according to the Volpe classification [14]

- periventricular leukomalacia (PVL): evaluated at any age by ultrasounds (cystic periventricular white matter lesions) or by Magnetic Resonance Imaging (periventricular high-intensity areas on T2-weighted images and atrophy of the cerebral white matter predominantly at the peritrigonal region)

- respiratory distress syndrome (RDS): oxygen requirement increasing during the first 24 hours, typical radiological pattern such as reduced air content, reticulogranular pattern of the lung air and bronchogram
- patent ductus arteriosus (PDA): clinical evidence of left to right PDA shunt or ecocolorDoppler evidence of PDA with evidence of left to right ductal shunting

- early or late onset sepsis:

- early: bacterial and/or fungal infections, diagnosed by means of a positive culture of blood and/or cerebrospinal fluid, within the first three days of life,

- late sepsis: if diagnosed, after the third day of life

- moderate or severe BPD, in accordance with the definition of Jobe and Bancalari [15]

- moderate BPD is determined as the need for $<30 \%$ oxygen at 36 week postmenstrual age (PMA) or discharge whichever comes first

- severe BPD is determined as the need for $\geq 30 \%$ oxygen and/or positive pressure (NCPAP or IPPV) at 36 week PMA or discharge whichever comes first

This is a prospective non-interventional survey, the participating neonatal intensive care unit assisted the newborns in accordance with their own protocols; therefore the management and the care of the patients in each center varied one from the other.

Only the eye examinations were standardized: all the participating centers have a staff of pediatric ophthalmologists. Following pupil dilation with cyclopentolate hydrochloride $0.2 \%$ and phenylephrine hydrochloride $1 \%$, pediatric ophthalmologists performed indirect ophthalmoscopies using scleral depression, if required, to visualize the retinal periphery, at weekly intervals, starting from the $4^{\text {th }}$ week of life until complete retinal vascularization occurred [12].

Ophthalmologists diagnosed ROP according to the ICROP report and classified the severity of ROP on the basis of:

Zone:

- Posterior: ROP in Zone I and posterior Zone II (P-ROP) [16]

- other zones: ROP in other Zones (OZ-ROP)

Presence of pre-plus (p-PD) or plus disease (PD) [12].

The classification based on Zone and on the presence of plus or pre-plus disease was chosen in order to reduce the variability in the classification of ROP among the various centers participating in the trial.

In case of surgical intervention, ophthalmologists reported the type of intervention carried out (Laser-therapy, Cryo-therapy) and the number of ablative surgical treatments performed. The outcome was defined "adverse" if total or partial retinal detachment or macular fold occurred, while normal anatomy (no detachment or macular fold) was defined as "a favorable outcome".

Univariate and multivariate logistic regression models were used to estimate the odds ratios (ORs) and the 
p-values for the association between ROP and the clinical parameters of the patients. Initially, the models were used to evaluate the independent predicting factors for developing ROP of any stage; the independent parameters associated with the evolution of the disease were also studied. Moreover, ORs were used to describe the characteristics of the infants that were candidates for the laser treatment. Sample size was calculated to detect a difference equal or greater than $15 \%$ in relative frequencies of different groups, with 5\% significance level and a power of $80 \%$.

A P value $<0.05$ was considered significant. All statistical analysis was performed with Stata software 9.0 (Stata Corporation, 1999, Texas, U.S.A.).

\section{Results}

The study involved $421 \mathrm{VPI}$; the spreadsheets were not completed in full for each newborn, with a rate of incompleteness for each parameter between $4 \%$ and $15 \%$. Birth weight, gestational age and ROP description were considered mandatory, moreover newborns with more than $10 \%$ missing data were not included in the sample.

Table 1 shows the distribution of birth weight and gestational age, and the clinical features of the study population.

All infants underwent the eye examinations in accordance with the guidelines. Ophthalmological screening was started at an average of 30 weeks of postmenstrual age. ROP was diagnosed in 265 newborns (62.9\%). At the univariate analysis (Table 2) GA $(p=0.008)$, BW $(p=0.007)$, PDA $(p=0.002)$, IVH $(p=0.001)$, early and late onset sepsis $(p=0.001), \operatorname{BPD}(p=0.002)$ and EPO therapy $(\mathrm{p}<0.001)$, showed a significant association with the occurrence of ROP.

Following the multivariate analysis only EPO-therapy $(\mathrm{p}<0.0001)$ and IVH $(\mathrm{p}=0.003)$ were significantly associated with ROP (Table 3). P-ROP was diagnosed in 102 cases (24.2\%); the ROP Zone was not reported in 10 cases; 7 of these infants underwent surgical treatment and all of them had a favorable outcome (Figure 1).

Gestational age $(p=0.002)$, sepsis $(p=0.002)$ and BPD $(\mathrm{p}=0.02)$ were significantly associated with P-ROP. At the multivariate analysis, gestational age $\leq 24$ weeks $(p=0.011)$ and sepsis ( $\mathrm{p}=0.002)$ appeared to be independent factors leading to P-ROP (Table 4).

PD was diagnosed in 79 newborns; 56 of them were affected by P-ROP (55\%) and 19 were affected by OZROP, (in 4 infants ROP Zone was not reported) (Figure 1).

p-PD was diagnosed in 17 newborns with P-ROP, in 33 infants with OZ-ROP and in 5 patients the zone of ROP was unknown (Figure 1). These differences were statistically significant $(\mathrm{p}<0.0001)$.

Eighty-nine infants underwent surgery (34\% of the 265 newborns with ROP); 59 of them (66.3\%) showed a P-ROP and 23 (25.8\%) an OZ-ROP (Figure 1). This difference was statistically significant ( $\mathrm{p}<0.0001)$.

Zone of ROP, gestational age, birth weight and sepsis were significantly associated with need of surgery at the univariate analysis; following the multivariate analysis only P-ROP was an independent factor associated with the need for surgical treatment $(p<0.0001)$. Birth weight

Table 1 Population characteristics

\begin{tabular}{|c|c|c|c|c|c|}
\hline Parameters & $\mathrm{N}^{\circ}$ of newborns & $\%$ & Parameters & $\mathrm{N}^{\circ}$ of newborns & $\%$ \\
\hline GA (weeks) & & & RDS & 384 & $99.7 \%$ \\
\hline $22-23-24$ & 92 & $22.6 \%$ & PDA & 251 & $65.0 \%$ \\
\hline 25 & 102 & $24.2 \%$ & $\mathrm{IVH}$ & 167 & $43.5 \%$ \\
\hline 26 & 134 & $31.8 \%$ & LPV & 99 & $26.7 \%$ \\
\hline \multirow{2}{*}{$\geq 27$} & 90 & $21.4 \%$ & Fungal Sepsis & 46 & $11.4 \%$ \\
\hline & & & Bacterial Sepsis & 178 & $44.2 \%$ \\
\hline $\mathrm{BW}(\mathrm{g})$ & & & $\mathrm{BPD}$ & 208 & $54.9 \%$ \\
\hline $300-450$ & 9 & $2.1 \%$ & Blood transfusions & 357 & $89.9 \%$ \\
\hline $451-600$ & 70 & $16.6 \%$ & EPO therapy & 210 & $55.6 \%$ \\
\hline $601-750$ & 167 & $39.7 \%$ & Mechanical ventilation ( > 7 days) & 258 & $69.2 \%$ \\
\hline$>750$ & 175 & $41.6 \%$ & NPT ( > 7 days) & 303 & $80.6 \%$ \\
\hline Male & 182 & $45.5 \%$ & $\mathrm{ROP}$ & 265 & $62.9 \%$ \\
\hline Inborn & 358 & $88.0 \%$ & $P-R O P$ & 102 & $24.2 \%$ \\
\hline APGAR score 5 th minute $\leq 7$ & 176 & $47.7 \%$ & Preplus disease & 55 & $13.1 \%$ \\
\hline PROM & 122 & $31.9 \%$ & Plus disease & 79 & $18.8 \%$ \\
\hline Chorioamnionitis & 93 & $27.8 \%$ & Laser treatment & 89 & $21.1 \%$ \\
\hline Antenatal steroids & 331 & $84.0 \%$ & Adverse outcome & 14 & $3.3 \%$ \\
\hline
\end{tabular}


Table 2 Association between ROP and neonatal parameters: logistic univariate analysis

\begin{tabular}{|c|c|c|c|c|}
\hline \multirow[t]{2}{*}{ Parameters } & ROP & No ROP & \multicolumn{2}{|c|}{ Univariate analysis } \\
\hline & \multicolumn{2}{|c|}{ n newborns (\%) } & OR & $p$-value \\
\hline $\mathrm{GA} \leq 24$ weeks & $71(75 \%)$ & $24(25 \%)$ & 2.01 & 0.008 \\
\hline $\mathrm{BW} \leq 750 \mathrm{~g}$ & $168(68 \%)$ & $78(32 \%)$ & 1.73 & 0.007 \\
\hline Male gender & $111(45 \%)$ & $71(46 \%)$ & 0.96 & 0.848 \\
\hline Inborn & 217 (86\%) & $141(90 \%)$ & 0.68 & 0.238 \\
\hline APGAR score 5 th minute $\leq 7$ & $125(56 \%)$ & $72(49 \%)$ & 1.31 & 0.205 \\
\hline PROM & $78(34 \%)$ & $44(29 \%)$ & 1.22 & 0.380 \\
\hline Chorioamnionitis & $60(31 \%)$ & $33(23 \%)$ & 1.47 & 0.130 \\
\hline Antenatal steroids & 198 (81\%) & $133(88 \%)$ & 0.59 & 0.085 \\
\hline RDS & $234(100 \%)$ & $150(100 \%)$ & \multicolumn{2}{|c|}{ Not applicable } \\
\hline PDA & $167(66 \%)$ & $84(34 \%)$ & 1.96 & 0.002 \\
\hline $\mathrm{IVH}$ & $118(71 \%)$ & 49 (29\%) & 2.10 & 0.001 \\
\hline LPV & $44(19 \%)$ & $55(38 \%)$ & 1.22 & 0.543 \\
\hline Sepsis & $134(70 \%)$ & $57(30 \%)$ & 2.02 & 0.001 \\
\hline BPD & $142(61 \%)$ & $66(45 \%)$ & 1.94 & 0.002 \\
\hline Blood transfusions & $217(90 \%)$ & $140(90 \%)$ & 0.93 & 0.833 \\
\hline EPO therapy & $147(70 \%)$ & $63(30 \%)$ & 2.39 & $<0.0001$ \\
\hline Mechanical ventilation (>7 days) & $157(71 \%)$ & $101(67 \%)$ & 1.20 & 0.432 \\
\hline NPT ( > 7 days) & 185 (83\%) & $118(78 \%)$ & 1.37 & 0.234 \\
\hline
\end{tabular}

below 750 g showed a borderline significance $(\mathrm{p}=0.054)$, while gestational age $(\mathrm{p}=0.946)$ and sepsis $(\mathrm{p}=0.188)$ were not statistically related to the requirement of laser therapy. The use of EPO was not associated with surgical treatment: $54 \%$ of the surgically treated infants and $68.2 \%$ of the non-treated infants received EPO.

PD was diagnosed in $87.5 \%$ of the surgically treated infants and p-PD in $12.5 \%$ of cases. None of the newborns without PD or p-PD underwent surgery. One hundred seventy newborns with ROP were not surgically treated: PD was diagnosed in only 2 and p-PD in 41 (21.1\%)(Figure 1).

Ophthalmologists performed surgical therapy between the $32^{\text {nd }}$ and $34^{\text {th }}$ weeks of gestation: laser-therapy, argon laser $532 \mathrm{~nm}$ or diode laser $810 \mathrm{~nm}$, and

Table 3 Association between ROP and neonatal parameters: logistic multivariate analysis

\begin{tabular}{cccccc}
\hline Parameters & \multicolumn{2}{c}{ ROP } & No ROP & & \multicolumn{2}{c}{ Multivariate analysis } \\
\cline { 2 - 3 } & \multicolumn{2}{c}{ n newborns (\%) } & & OR & p-value \\
\hline GA $\leq 24$ weeks & $71(75 \%)$ & $24(25 \%)$ & & 1.58 & 0.147 \\
BW $\leq 750 \mathrm{~g}$ & $168(68 \%)$ & $78(32 \%)$ & & 1.63 & 0.053 \\
PDA & $167(66 \%)$ & $84(34 \%)$ & & 1.21 & 0.455 \\
IVH & $118(71 \%)$ & $49(29 \%)$ & & 2.10 & 0.003 \\
Sepsis & $134(70 \%)$ & $57(30 \%)$ & & 1.43 & 0.135 \\
BPD & $142(68 \%)$ & $66(32 \%)$ & & 1.32 & 0.249 \\
EPO & $147(70 \%)$ & $63(30 \%)$ & & 2.93 & $<0.0001$ \\
\hline
\end{tabular}

cryotherapy. In all cases the laser-therapy was performed; in 8 cases cryotherapy was attempted as additional treatment. Four newborns with P-ROP required vitrectomy following laser and cryotherapy (1.5\% of all newborn with ROP). All patients showed P-ROP in Zone 1. The outcome was evaluated as favorable in 251 nontreated infants (94\%) and in $68(86.7 \%)$ of surgically treated infants. Adverse outcomes occurred in 14 patients $(3.3 \%$ of total population, $5.3 \%$ of infants with ROP and $14.6 \%$ of surgically treated infants): 11 had bilateral and 3 unilateral retinal detachment. All 14 had PROP and underwent surgery (Figure 1).

\section{Discussion}

ROP widely affected extremely premature infants: the occurrence of P-ROP represented the main risk factor for surgical treatment. A considerable number of newborns required surgery; laser therapy was mostly effective and adverse outcomes were rare.

Our incidence data differ from those of the Cryotherapy for Retinopathy of Prematurity Cooperative Group trial and from those of the ETROP study $[9,17]$; these studies reported a higher incidence of ROP but they were conducted prior to the introduction of the current guidelines to prevent ROP [18].

Other studies showed results similar to ours [19-21]. The 2009 Vermont-Oxford Network Report showed an incidence of ROP superimposable on our results [22]. 


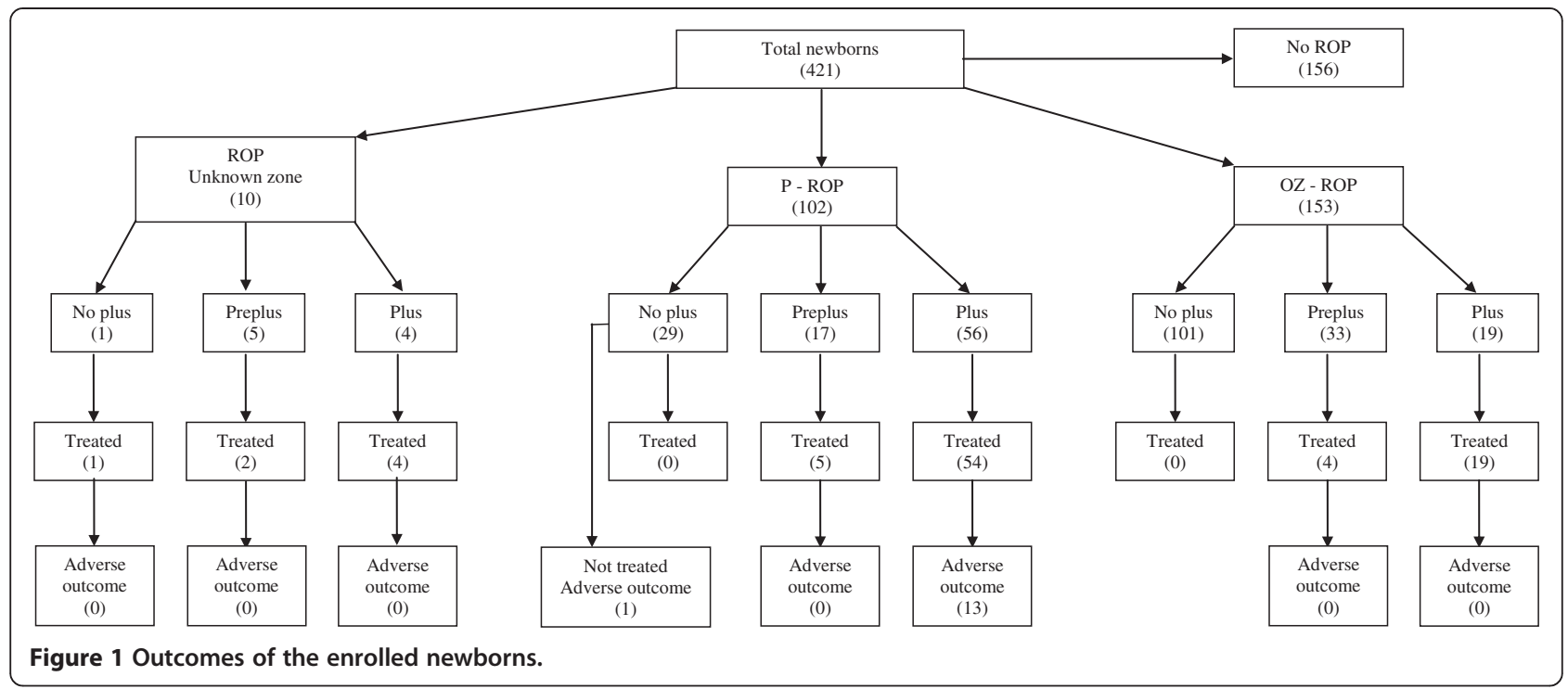

In the multivariate analysis EPO therapy and IVH significantly associated with the incidence of ROP; birth weight showed only a borderline association. EPO therapy was a risk factor for ROP, but not for P-ROP. Shah et al. did not find any significant difference between EPO therapy and the presence or severity of ROP [23]. Before the "EPO era", blood transfusions were more common in NICUs and some researchers considered them as a risk factor for developing ROP $[24,25]$. Suk et al. in a multiple regression model found that blood transfusions were a significant independent risk factor for the development of ROP. Currently it is not clear if the therapy with EPO is advantageous compared to the blood transfusions in treating anemic preterm infants [26]. Schneider et al. showed that EPO therapy does not increase the number and the severity of ROP cases, while it may reduce the number of blood transfusions
[27]. Recently, in a mouse model of proliferative retinopathy, Chen et al. studied the role of EPO in suppression of retinal neovascularization; they proposed the hypothetic intravitreal use of EPO in proliferative retinopathy [28].

In our study EPO administration was a factor involved in the development of ROP, while it was not a factor related to the severity of the disease: it was not significantly associated to P-ROP and to the necessity of surgical intervention. GA $\leq 24$ weeks and sepsis were significant risk factors for developing P- ROP. Even though gestational age was not directly related to the ROP, it triggered P-ROP and therefore was one of the main causes of the more severe type of the disease [29].

It is noteworthy that BPD was not associated with the ROP, nor with the more aggressive kind of ROP, even though the use of oxygen is particularly involved in ROP

Table 4 Association between P-ROP or treated newborn and neonatal parameters: logistic univariate and multivariate analysis

\begin{tabular}{|c|c|c|c|c|c|c|}
\hline \multirow[t]{2}{*}{ Parameters } & $P$ - ROP & OZ - ROP & \multicolumn{2}{|c|}{ Univariate analysis } & \multicolumn{2}{|c|}{ Multivariate analysis } \\
\hline & \multicolumn{2}{|c|}{ n newborns (\%) } & OR & p-value & OR & $\mathrm{p}$-value \\
\hline $\mathrm{GA} \leq 24$ weeks & $37 / 71$ (52.1\%) & 29/71 (40.8\%) & 2.43 & 0.002 & 2.30 & 0.011 \\
\hline Sepsis & $60 / 134(44.8 \%)$ & $68 / 134(50.7 \%)$ & 2.35 & 0.002 & 2.64 & 0.002 \\
\hline $\mathrm{BPD}$ & $57 / 142(40.1 \%)$ & 79/142 (55.6\%) & 2.01 & 0.020 & 1.53 & 0.182 \\
\hline
\end{tabular}

Association between zones and significant neonatal parameters: univariate and multivariate logistic analysis

\begin{tabular}{|c|c|c|c|c|c|c|}
\hline \multirow[t]{2}{*}{ Parameters } & Treatment & No treatment & \multicolumn{2}{|c|}{ Univariate analysis } & \multicolumn{2}{|c|}{ Multivariate analysis } \\
\hline & \multicolumn{2}{|c|}{ n newborns (\%) } & OR & p-value & OR & p-value \\
\hline$P-R O P$ & $59 / 89(66.3 \%)$ & $35 / 142(24.6 \%)$ & 7.84 & $<0.0001$ & 7.30 & $<0.0001$ \\
\hline EG $\leq 24$ weeks & $33 / 89(37.1 \%)$ & $33 / 142$ (23.2\%) & 1.95 & 0.024 & 0.97 & 0.946 \\
\hline $\mathrm{BW} \leq 750 \mathrm{~g}$ & 69/89 (77.5\%) & 79/142 (55.6\%) & 2.75 & 0.001 & 2.07 & 0.054 \\
\hline Sepsis & $54 / 89(60.7 \%)$ & $61 / 142(42.9 \%)$ & 2.36 & 0.003 & 1.58 & 0.188 \\
\hline
\end{tabular}

Association between laser treatment and significant neonatal parameters: univariate and multivariate logistic analysis 
pathogenesis. This may arise from the use of more accurate targets of oxygen saturation during oxygen-therapy, both in the first weeks of life, when hyperoxia is dangerous, and also during the following weeks, when hypoxia induces neovascularization. Some authors recommend monitoring oxygen therapy on the basis of gestational age and postnatal age: low-oxygen levels during early phases of life and high levels in the later phases [30].

Our data on the risk factors for P-ROP are consistent with the pathogenetic model recently proposed by Lee and Damman: in their review they concluded that exposure to perinatal infection/ inflammation is associated with an increased risk for ROP. Circulating products of infection and/or inflammation might directly damage the developing retina; moreover inflammation and/or oxidative stress might increase the risk of oxygen-associated ROP. This means that prenatal, perinatal, and postnatal systemic inflammation could sensitize the pre-ROP retina for subsequent insults, setting the stage for what is now called phase I and phase II of ROP pathogenesis. The authors concluded that strategies for targeting inflammatory responses might help in reducing the risk for ROP in extremely preterm infants [31].

In our study laser therapy was performed in all infants requiring surgery; most of these infants had a P-ROP. $\mathrm{PD}$ represented the main indicator for surgical intervention as also reported in the ICROP study [11].

In almost all cases, the infants with ROP associated with PD underwent surgical intervention; only 2 out of 75 newborns with PD were not treated with laser therapy. Moreover, occurrence of $\mathrm{p}-\mathrm{PD}$ represented an indication for surgical intervention; although it was more evident in the newborns affected by P-ROP than in OZ-ROP there was probably an overtreatment in some cases. PD was significantly higher in P-ROP than in OZ-ROP; therefore infants with P-ROP underwent surgery more frequently than infants with OZ-ROP. These observations confirm the severity of P-ROP.

The percentage of children treated with laser therapy in our population was equal to the percentage reported in a Malaysian study and double the number reported in a Swedish paper $[20,21]$. This variability of data may be due to the differences of the populations involved. As Darlow et al. in the Australian and New Zealand Neonatal Network argued, the discrepancy between the data reported in scientific literature may be attributed to a wide variability in the classification of ROP [32]. For this reason we classified the severity of ROP on the basis of zone and presence of PD or p-PD. Our protocol allowed us to classify ROP disease more clearly without the inter-individual differences of ophthalmologists.

Treatment was performed between the $32^{\text {nd }}$ and the $34^{\text {th }}$ weeks of gestation. The majority of surgically treated infants had a favorable outcome; this is encouraging even though Ruth Axer-Siegel and coll. reported $92.3 \%$ favorable outcomes following laser therapy in a cohort of 100 neonates, which is slightly better than our data [33]. It is important to underline that all 14 infants with an adverse outcome were $\leq 24$ weeks gestation, each one underwent almost one episode of sepsis and was affected by P- ROP: this confirms once more that P-ROP represents the most severe form of ROP and it is associated with the worst short term outcome.

\section{Conclusion}

In order to prevent severe ROP in very preterm infants, a multidisciplinary strategy is necessary: obstetricians should prevent preterm births and intrauterine infections; neonatologists should reduce the occurrence of septic diseases and should carefully monitor infant oxygen exposure. In all NICUs, a pediatric ophthalmologist should periodically evaluate all very preterm infants from the $28^{\text {th }}$ day of postnatal age. The follow-up of infants with Zone I and Zone II posterior ROP needs to be particularly scrupulous since these infants are at high risk of surgical intervention and adverse outcome.

\section{Abbreviations}

OZ-ROP: ROP in any other Zones; PD: Presence of plus disease; p-PD: Presence of pre-plus disease; P-ROP: ROP in posterior Zone (Zone I and posterior Zone II).

\section{Competing interests}

The authors declare that they have no competing interests.

\section{Authors' contributions}

CB: Conception and design of the study, study coordination, analysis and interpretation of data, manuscript draft. CC: Analysis and interpretation of data, manuscript draft (ophthalmological section). EDP- SM: Statistical analysis. VB: Interpretation of data, manuscript draft. VC: Conception and design of the study. SC: Conception and design of the study. PET:

interpretation of data, manuscript draft, critical revision. All authors read and approved the final manuscript.

\section{Acknowledgements}

The full list of participating centers (listed in alphabetical order by city) and investigators includes:

Alessandria: A.O. SS. Antonio e Biagio e C. Arrigo: D. Dolcino M.D., D. Gazzolo M.D.

Bergamo: Osp.Riuniti: F. Fabiani M.D., S. Pedretti M.D., G. Mangili M.D. Brescia: Osp.Civili: G. Iacono M.D., Clinica Oculistica Università degli Studi: P. Rossi Brunori M.D., G. Nascimbeni M.D.

Como: A.O. S. Anna: L. Spallino M.D., D. Merazzi M.D.

Foggia: Osp. di Maternità e Pediatrico: R. Magaldi M.D., M. Rinaldi M.D Genova: Istituto Gaslini UTI-CNR: E. Priolo M.D., P. Capris M.D.

Milano: Osp.V. Buzzi: S. Gambaro M.D., I. Daniele M.D.; Fondazione IRCCS Ca'Granda Osp.Policlinico Università degli Studi: S. Osnaghi M.D., G. Araimo M.D.; Osp. Niguarda Ca'Granda: E. Piozzi M.D., M. Mazza M.D., L. Ilardi M.D.

Modena: A.O. Universitaria Policlinico: C. Chiesi M.D., M.F. Roversi M.D.

Monza: A.O. S.Gerardo dei Tintori: B. Cavallotti M.D.; Fondazione MBBM:

S. Malguzzi M.D.

Napoli: Osp. Fatebenefratelli: G. Salvia M.D.; M.G. Sarnelli M.D.

Palermo: Osp. Bucchieri La Ferla Fatebenefratelli: O. Ganguzza M.D.

Pavia: Università degli Studi - IRCCS Policlinico S. Matteo: R. Guagliano M.D.,

D. Barillà M.D., L. Bollani M.D.

Perugia: Università degli Studi: C. Cagini M.D., Azienda Ospedaliera:

C. Germini M.D. 
S.Giovanni Rotondo (FG): Casa Sollievo della Sofferenza: A. Gatta M.D., A. Laborante M.D.

Torino: Osp. M.Vittoria: L. Fogli M.D., G. Caroni M.D., G. Anselmetti M.D. Università degli Studi: A. Soldi M.D., L. Ferrero M.D., M.A. Maestri M.D. Udine: A.O. S. Maria della Misericordia: V. Gregorutti M.D., Boiti C. M.D., F. Miani M.D.

Verona: Policlinico Borgo Roma: E.M. Padovani M.D; Osp. Borgo Trento: P. Sonetti M.D.,

Azienda Universitaria: S. Pignatto M.D., E. Gusson M.D., C. Mansoldo M.D.

\section{Author details}

${ }^{1}$ Neonatology and Neonatal Intensive Care Unit Fondazione MBBM, Monza, Italy. ${ }^{2}$ Ophtalmology Department, S. Gerardo Hospital, Monza, Italy. ${ }^{3}$ Medical Physics Department, S. Gerardo Hospital, Monza, Italy. ${ }^{4}$ Executive board of the Italian "ROP Study Group", Torino, Italy. ${ }^{5}$ Pediatric Department,

Santobono-Annunziata-Pausilipon-Hospital, Naples, Italy.

Received: 21 March 2013 Accepted: 4 July 2013

Published: 9 July 2013

\section{References}

1. Fanaroff AA, Hack M, Walsh MC: The NICHD neonatal research network: changes in practice and outcomes during the first 15 years. Semin Perinatol 2003, 27:281-287.

2. Gilbert C: Retinopathy of prematurity: a global perspective of the epidemics, population of babies at risk and implications for control. Early Hum Dev 2008, 84:77-82

3. Campbell K: Intensive oxygen therapy as a possible cause of retrolental fibroplasia; a clinical approach. Med J Aust 1951, 2:48-50.

4. McGregor ML, Bremer DL, Cole C, McClead RE, Phelps DL, Fellows RR, Oden $\mathrm{N}$ : Retinopathy of prematurity outcome in infants with prethreshold retinopathy of prematurity and oxygen saturation $>94 \%$ in room air: the high oxygen percentage in retinopathy of prematurity study. Pediatr 2002, 110:540-544.

5. Chen J, Smith LE: Retinopathy of prematurity. Angiogenesis 2007, 10:133-140.

6. McLoone E, O'Keefe M, McLoone S, Lanigan B: Long term functional and structural outcomes of laser therapy for retinopathy of prematurity. Br J Ophthalmol 2006, 90:754-759.

7. Flynn JT, Bancalari E, Snyder ES, Goldberg RN, Feuer W, Cassady J, Schiffman J, Feldman HI, Bachynski B, Buckley E, et al: A cohort study of transcutaneous oxygen tension and the incidence and severity of retinopathy of prematurity. N Engl J Med 1992, 326:1050-1054.

8. Chow LC, Wright KW, Sola A: Can changes in clinical practice decrease the incidence of severe retinopathy of prematurity in very low birth weight infants? Pediatr 2003, 111:339-345.

9. Good WV, Hardy RJ, Dobson V, Palmer EA, Phelps DL, Quintos M, Tung B The incidence and course of retinopathy of prematurity: findings from the early treatment for retinopathy of prematurity study. Pediatr 2005, 116:15-23.

10. Tasman W: Multicenter trial of cryotherapy for retinopathy of prematurity. Arch Ophthalmol 1988, 106:463-464.

11. An International Committee for the Classification of Retinopathy of Prematurity: The International Classification of Retinopathy of Prematurity revisited. Arch Ophthalmol 2005, 123:991-999.

12. Section on Ophthalmology. American Academy of Pediatrics, American Academy of Ophthalmology, American Association for Pediatric Ophthalmology and Strabismus. Screening examination of premature infants for retinopathy of prematurity. Pediatr 2006, 117:572-576. Erratum in: Pediatrics. 2006;2118(2003):1324.

13. Early Treatment For Retinopathy Of Prematurity Cooperative Group: Revised indications for the treatment of retinopathy of prematurity: results of the early treatment for retinopathy of prematurity randomized trial. Arch Ophthalmol 2003, 121:1684-1694.

14. Volpe JJ: Neurology of the Newborn. 2nd edition. Philadelphia: WB Saunders; 1987.

15. Jobe $A H$, Bancalari E: Bronchopulmonary dysplasia. Am J Respir Crit Care Med 2001, 163:1723-1729.

16. Axer-Siegel R, Snir M, Cotlear D, Maayan A, Frilling R, Rosenbaltt I, Weinberger D, Kremer I, Sirota L: Diode laser treatment of posterior retinopathy of prematurity. Br J Ophthalmol 2000, 84:1383-1386.
17. Palmer EA, Flynn JT, Hardy RJ, Phelps DL, Phillips CL, Schaffer DB, Tung B: Incidence and early course of retinopathy of prematurity. The Cryotherapy for Retinopathy of Prematurity Cooperative Group. Ophthalmol 1991, 98:1628-1640.

18. Bullard SR, Donahue SP, Feman SS, Sinatra RB, Walsh WF: The decreasing incidence and severity of retinopathy of prematurity. J AAPOS 1999, 3:46-52.

19. Teed RG, Saunders RA: Retinopathy of prematurity in extremely premature infants. J AAPOS 2009, 13:370-373.

20. Austeng D, Kallen KB, Ewald UW, Jakobsson PG, Holmstrom GE: Incidence of retinopathy of prematurity in infants born before 27 weeks' gestation in Sweden. Arch Ophthalmol 2009, 127:1315-1319.

21. Choo MM, Martin FJ, Theam LC CUT: Retinopathy of prematurity in extremely low birth weight infants in Malaysia. J AAPOS 2009, 13:446-449.

22. 2009 Database Summaries and VLBW. Quality Management Report Revised March 2011. Burlington, Vermont: Vermont Oxford Network; 2011.

23. Shah N, Jadav P, Jean-Baptiste D, Weedon J, Cohen LM, Kim MR: The effect of recombinant human erythropoietin on the development of retinopathy of prematurity. Am J Perinatol 2010, 27:67-71.

24. Valieva OA, Strandjord TP, Mayock DE, Juul SE: Effects of transfusions in extremely low birth weight infants: a retrospective study. J Pediatr 2009, 155:331-337. e331.

25. Cooke RW, Clark D, Hickey-Dwyer M, Weindling AM: The apparent role of blood transfusions in the development of retinopathy of prematurity. Eur J Pediatr 1993, 152:833-836.

26. Suk KK, Dunbar JA, Liu A, Daher NS, Leng CK, Leng JK, Lim P, Weller S, Fayard E: Human recombinant erythropoietin and the incidence of retinopathy of prematurity: a multiple regression model. J AAPOS 2008, 12:233-238

27. Schneider JK, Gardner DK, Cordero L: Use of recombinant human erythropoietin and risk of severe retinopathy in extremely low-birth -weight infants. Pharmacother 2008, 28:1335-1340.

28. Chen J, Connor KM, Aderman CM, Willett KL, Aspegren OP, Smith LE: Suppression of retinal neovascularization by erythropoietin siRNA in a mouse model of proliferative retinopathy. Invest Ophthalmol Vis Sci 2009, 50:1329-1335

29. Chen M, Citil A, McCabe F, Leicht KM, Fiascone J, Dammann CE, Dammann $\mathrm{O}$ : Infection, oxygen, and immaturity: interacting risk factors for retinopathy of prematurity. Neonatology 2011, 99:125-132.

30. Chen ML, Guo L, Smith LE, Dammann CE, Dammann O: High or low oxygen saturation and severe retinopathy of prematurity: a metaanalysis. Pediatr 2010, 125:e1483-1492.

31. Lee J, Dammann O: Perinatal infection, inflammation, and retinopathy of prematurity. Semin Fetal Neonatal Med 2012, 17:26-29.

32. Darlow BA, Elder MJ, Horwood LJ, Donoghue DA, Henderson-Smart DJ: Does observer bias contribute to variations in the rate of retinopathy of prematurity between centres? Clin Experiment Ophthalmol 2008, 36:43-46.

33. Axer-Siegel R, Maharshak I, Snir M, Friling R, Ehrlich R, Sherf I, Shalev B, Sirota $L$, Weinberger $D$ : Diode laser treatment of retinopathy of prematurity: anatomical and refractive outcomes. Retina 2008, 28:839-846.

doi:10.1186/1824-7288-39-43

Cite this article as: Borroni et al:: Survey on retinopathy of prematurity (ROP) in Italy. Italian Journal of Pediatrics 2013 39:43.

\section{Submit your next manuscript to BioMed Central and take full advantage of:}

- Convenient online submission

- Thorough peer review

- No space constraints or color figure charges

- Immediate publication on acceptance

- Inclusion in PubMed, CAS, Scopus and Google Scholar

- Research which is freely available for redistribution 